\title{
Medidas disciplinadoras na Educação Física Em diferentes níveis de ensino de Belo Horizonte
}

\author{
Giselle Foureaux ${ }^{*}$ \\ Cristina Carvalho de Melo* \\ FRANCO NocE ${ }^{* * *}$
}

\begin{abstract}
RESUMO: O objetivo deste trabalho foi analisar a eficácia das medidas disciplinadoras utilizadas por professores durante aulas de Educação Física. Os resultados mostraram que as medidas disciplinadoras mais eficazes foram "reforçar positivamente o aluno", "dialogar com o aluno", "organizar as aulas" e "estabelecer metas". As medidas menos eficazes foram: "punir com atividade física" $\mathrm{e}$ "ser indiferente ao aluno indisciplinado". Conclui-se que a eficácia das medidas disciplinadoras e o estilo ideal de liderança estão relacionados com a maturidade do grupo e a experiência dos professores.
\end{abstract}

Palavras-chave: Disciplina. Medidas disciplinadoras. Indisciplina. Educação Física escolar.

\section{Disciplinary measures in Physical Education At different education levels in Belo Horizonte}

\begin{abstract}
The objective of this work was to analyze the effectiveness of the disciplinary measures used by teachers during Physical Education classes. The results showed that the most effective disciplinary measures were "positive reinforcing of the student", "dia-
\end{abstract}

* Pós-doutora em Biologia Celular e em Fisiologia e Farmacologia pela Universidade Federal de Minas Gerais (UFMG), especialista em atividades físicas para grupos especiais pelo Centro Universitário de Belo Horizonte/ UNI-BH. Atualmente é professora departamento de Morfologia do Instituto de Ciências Biológicas da UFMG. Belo Horizonte/MG - Brasil. E-mail: <gifoureaux@icb.ufmg.br>.

** Mestranda em Estudos do Lazer pela Universidade Federal de Minas Gerais. Atualmente é co-coordenadora do Projeto Pilates CEU/UFMG e tutora do curso de formação em políticas sociais do programa Esporte e Lazer da Cidade e Vida Saudável. Belo Horizonte/MG - Brasil. E-mail: <carvalho.cristina@gmail.com>.

*** Doutor em Psicobiologia pela Universidade Federal de São Paulo. É professor da Universidade Federal de Minas Gerais, onde atua no Programa de Pós-Graduação em Ciências do Esporte. Belo Horizonte/MG Brasil. E-mail: <carvalho.cristina@gmail.com>. 
loguing with the student", "organizing classes" and "setting goals". The least effective measures were: "to punish with physical activity" and "to be indifferent to the undisciplined student". We concluded that the effectiveness of the disciplinary measures and the ideal style of leadership are related to the maturity of the group and the experience of the teachers.

Keywords: Discipline. Disciplinary measures. Indiscipline. Physical education in school.

\section{Medidas disciplinarias en la Educación Física}

En diferentes niveles de enseñanza de Belo Horizonte

RESUMEN: El objetivo de este trabajo es analizar la eficacia de las medidas disciplinarias utilizadas por los profesores en las clases de Educación Física. Los resultados muestran que las medidas disciplinarias más eficaces son "reforzar positivamente al alumno", "dialogar con el alumno", "organizar las clases" y "establecer metas". Las medidas menos eficaces son: "punir con actividad física" y "ser indiferente al alumno indisciplinado". La conclusión es que la eficacia de las medidas disciplinarias y el estilo ideal de liderazgo están relacionados a la madurez del grupo y a la experiencia de los profesores.

Palabras clave: Disciplina. Medidas disciplinarias. Indisciplina. Educación Física escolar.

\section{Mesures disciplinaires en éducation physique}

Dans diffférents niveaux d'enseignement de Belo Horizonte

RÉSUMÉ: Ce travail visait à analyser l'efficacité des mesures disciplinaires utilisées par les professeurs durant les cours d'éducation physique. Les résultats ont montré que les mesures disciplinaires les plus efficaces consistaient à "renforcer positivement l'élève", "dialoguer avec l'élève", "organiser les cours" et "fixer des objectifs". Les mesures les moins efficaces furent repérées comme étant: "punir par une activité physique" et "être indifférent à l'élève indiscipliné". D’où la conclusion selon laquelle l'efficacité des mesures discipli- 
naires et le style ideal de leadership sont liés à la maturité du groupe et à l'expérience des professeurs.

Mots-clés: Discipline. Mesures disciplinaires. Indiscipline. Éducation physique scolaire.

\section{Introdução}

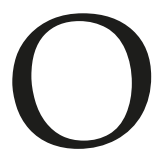

fenômeno da disciplina é complexo e amplo, uma vez que está presente em diversos planos da atuação humana: no plano social, psicológico, educacional, entre outros. Trata-se da regra de conduta individual ou coletiva e a sanção que tutela a sua observância (Brito, 1993). No contexto educacional, a disciplina é imprescindível para o desenvolvimento de qualquer atividade, seja ela individual ou em grupo (Boarini, 2013). É possível afirmar, inclusive, que dentre as adversidades e diversidades encontradas em uma sala de aula, a maior delas é, sem dúvida, a indisciplina (Pires, 1999). Tal fator tornou-se um grande desafio e cada vez mais tem sido alvo de preocupação das escolas, pais e professores (Boarini, 2013). O ensino, individual ou coletivo, deve estar comprometido com a ação pedagógica e proporcionar um vínculo saudável na relação interpessoal (Koehler, 2008).

A autoridade, intimamente vinculada à (in)disciplina (Novais, 2004), pressupõe uma relação assimétrica de poder, na qual aquele que ensina (o docente), exerce uma autoridade sobre aquele que aprende, o aluno (De La Taille, 1999). Esta autoridade advém tanto do papel social do professor quanto do domínio que possui sobre o conteúdo com o qual está trabalhando; ou seja, a autoridade se constitui a partir de uma aliança entre conhecimento e experiência na condução da turma (Novais, 2004). A autoridade implica uma relação hierárquica, onde o professor tem como função emitir ordens coerentes e eficientes para o bom andamento do processo de ensino-aprendizagem, e o aluno tem a função de segui-las, desde que sejam justas e se mostrem eficazes (Novais, 2004; De La Taille, 1999). Tiba (1996) afirma que a autoridade precisa ser algo natural, que deve existir sem descargas de adrenalina, seja para impor ou se submeter, pois quando a autoridade é reconhecida espontaneamente por ambas as partes, o relacionamento se desenvolve sem atropelos.

É importante que exista autoridade para manter a disciplina dentro de uma sala de aula, entretanto, esta tem sido frequentemente confundida com o autoritarismo. De acordo com Dopp; Pontes-Ribeiro (2014), o autoritarismo está relacionado com controle excessivo, ameaças e distorções dos princípios democráticos; onde o aluno conceberá o professor como um manipulador. Enquanto a autoridade consiste no direito legitimado de comandar que confere a uma determinada pessoa, a responsabilidade de tomar 
decisões; o autoritarismo é reconhecido como abuso de poder, no qual a pessoa se excede no uso desse poder (Amestoy et al., 2009). Para haver disciplina, é necessária a presença de uma autoridade saudável, tendo em vista que o fator que diferencia o autoritarismo da autoridade (adotada para que a pessoa se torne mais educada ou disciplinada) é o respeito (Tiba, 1996). O ideal seria o exercício de uma autoridade consciente, para que, assim, a disciplina possa ser mais interativa e marcada por participação, respeito, responsabilidade, construção do conhecimento, formação do caráter e da cidadania (Pires, 1999).

Conforme pesquisa realizada por Brito (1993), o conceito de disciplina pode estar vinculado a aspectos negativos e positivos. O primeiro está associado com punição, controle e contenção de comportamentos inadequados do ponto de vista social, tendo como meio o castigo. $\mathrm{O}$ aspecto positivo, por sua vez, se refere à utilização dos processos motivadores, excluindo a necessidade de vigilância e controle externo. Alguns fatores são cruciais para determinar se a disciplina será positiva ou negativa, como por exemplo: o tom de voz que o professor utiliza, a quantidade e qualidade dos estímulos fornecidos, o momento das intervenções e os momentos em que ele exerce um comportamento mais opressivo ou um comportamento voltado para instrução e reforço (Brandão; Carchan, 2010).

Observado sob esse prisma, almejar comportamento disciplinado positivo no contexto da Educação Física escolar não pode ser sinônimo de aspirar comportamento padronizado, rígido e punitivo. Para exemplificar, pensemos nas regras e proibições de um determinado esporte; as regras que visam obtenção da disciplina acerca da prática do esporte não apenas o regulamentam, mas possibilitam o jogo (Carvalho, 1996). Se, por outro lado, nenhuma disciplina for exigida e atendida, e cada qual fizer o que bem entender, não haverá outro desfecho, senão o caos (Boarini, 2013). Em outras palavras, o professor deve objetivar alcançar o comportamento disciplinado positivo dos seus alunos para manter a ordem, sem, contudo, impedir a criatividade. A liderança efetiva, aqui entendida como a arte de conseguir direcionar um grupo para a realização de tarefas em prol de um objetivo comum (Noce et al., 2011), é aquela que consegue abranger as necessidades dos liderados e as particularidades do contexto da ação. Com isso, o líder será capaz de atingir o sucesso e promover experiências positivas aos participantes (Gomes; Paiva, 2010). Brandão \& Carchan (2010) afirmam que o estilo de liderança do professor, em geral, pode ser: autocrático, em que o professor (líder) toma decisões sem consultar a equipe; e democrático, cujo processo de decisão também tem participação dos membros da equipe. Araújo e Ferreira (2009) consideram que os resultados e o sucesso de uma equipe dependem, pelo menos em parte, dos estilos de liderança.

Logo, o estilo de liderança adotado pelo professor e as medidas disciplinadoras escolhidas por ele não devem ser uma disputa de poder entre o professor e o aluno, mas propiciar a organização do trabalho coletivo durante as aulas, para que, dessa forma, seja possível realizar a construção do conhecimento e desenvolver a formação integral do 
aluno. Diante do que foi exposto e do fato da disciplina interferir, bem como sofrer interferências em vários campos do saber, o objetivo deste trabalho foi analisar a eficácia das medidas disciplinadoras utilizadas pelo professor durante as aulas de Educação Física.

\section{Métodos}

Participaram do estudo professores de Educação Física de diferentes níveis de ensino, classificados como: infantil; fundamental 1: até a $4^{\text {a }}$ série; fundamental 2: da $5^{\text {a }}$ a $8^{\text {a }}$ série; médio: do $1^{\circ}$ ao $3^{\circ}$ ano. Todos os professores eram docentes de uma escola particular de Belo Horizonte e responderam apenas ao instrumento referente ao nível de ensino aos quais tinham experiência de ensino. O instrumento utilizado foi composto por uma ficha de dados pessoais para caracterização da amostra e pelo questionário de percepção da eficácia das medidas disciplinadoras (Brito, 1993). O questionário de percepção da eficácia das medidas disciplinadoras consta de 20 diferentes medidas, as quais o professor avaliou numa escala de quatro valores, sendo: 0-ineficaz; 1-pouco eficaz; 2-eficaz e 3-muito eficaz. As medidas foram avaliadas de acordo com o nível de ensino (infantil, fundamental 1, fundamental 2 e médio). Os dados foram coletados na própria escola em horários previamente agendados com os professores. Para a realização da pesquisa foi solicitada uma autorização à direção da escola. Os professores foram informados sobre todos os objetivos e procedimentos da pesquisa. O preenchimento do instrumento, bem como os resultados foram tratados de forma anônima. A participação foi voluntária e aqueles que concordaram em participar assinaram, previamente, um Termo de Consentimento Livre e Esclarecido. Esse consentimento estava de acordo com o proposto pelo Conselho Nacional de Saúde, resolução nº 196/96, sobre pesquisas envolvendo seres humanos, baseadas na declaração de Helsinque. Os dados demográficos de caracterização da amostra foram analisados através de estatística descritiva, composta por média, desvio padrão e distribuição de frequência de acordo com a natureza da variável. Para o questionário de percepção da eficácia das medidas disciplinadoras, foi utilizada uma análise de variância (ANOVA oneway) para comparar os níveis de ensino. Foi utilizado, para tabulação e para os cálculos, o pacote estatístico sPSs 11 for windows. 


\section{Resultados}

\section{Estilo de liderança predominante}

De uma forma geral, a análise do estilo de liderança preferencialmente adotado pelos professores, sem levar em consideração o nível de ensino, não demonstrou diferença estatística (estilo democrático: 45,8\% e estilo autocrático: 54,2\%) (Figura 1).

\section{Figura 1 - Estilo de liderança adotado, predominantemente, pelos professores}

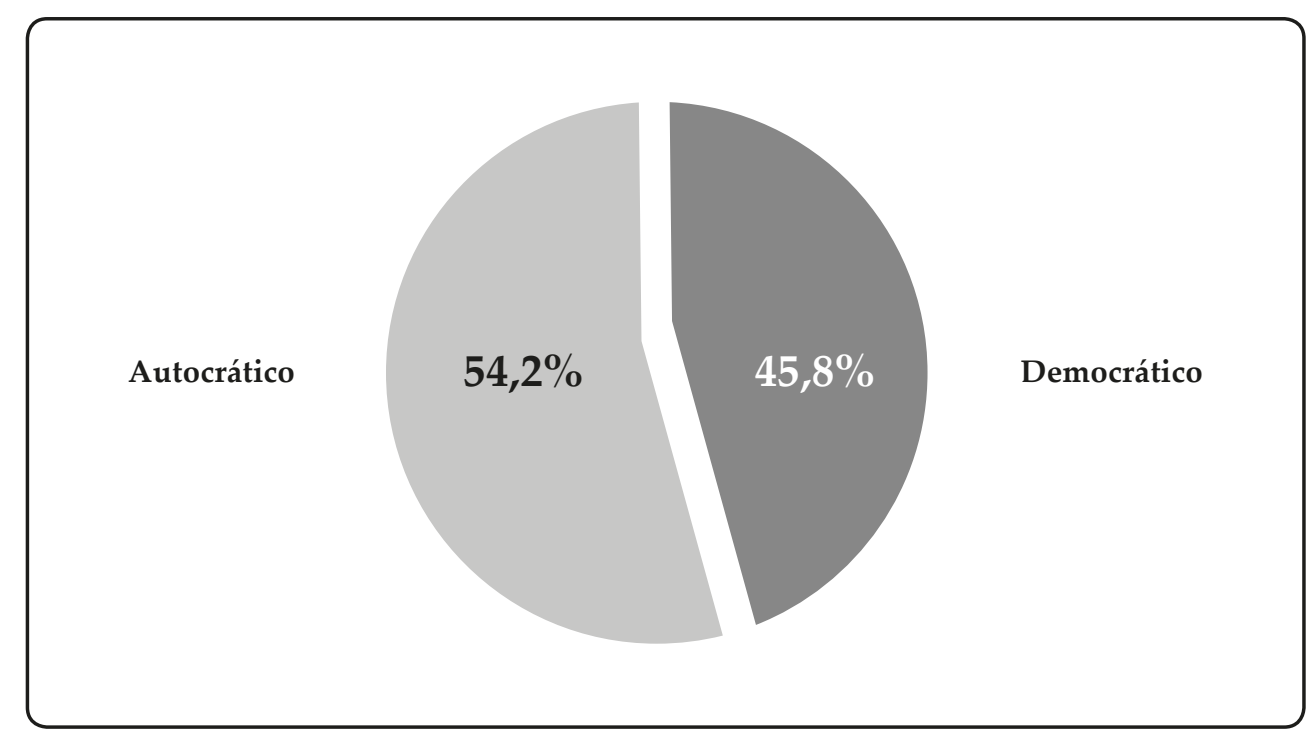

Ao analisar os estilos de liderança, de acordo com o nível de ensino ao qual o professor está inserido (Tabela 1), verificamos que os professores utilizam, predominantemente, o estilo democrático nas séries mais avançadas.

Tabela 1 - Estilo de liderança predominante adotado pelos professores de acordo com o nível de ensino em que atuam.

\begin{tabular}{|c|c|c|c|c|}
\hline & \multicolumn{2}{|c|}{ Democrático } & \multicolumn{2}{|c|}{ Autocrático } \\
\hline & $\mathbf{N}$ & $\%$ & $\mathbf{N}$ & $\%$ \\
\hline Infantil & 1 & $16,7 \%$ & 5 & $83,3 \%$ \\
\hline Fundamental 1 (até 4a série) & 1 & $14,3 \%$ & 6 & $85,7 \%$ \\
\hline $\begin{array}{l}\text { Fundamental } 2 \text { (da 5a a 8a } \\
\text { série) }\end{array}$ & 4 & $66,7 \%$ & 2 & $33,3 \%$ \\
\hline Médio (do 1o ao 3o ano) & 5 & $100,0 \%$ & & \\
\hline
\end{tabular}




\section{Eficácia das medidas disciplinadoras}

Grande parte do resultado obtido por um líder ao conduzir o grupo para uma meta pode ser atribuída às medidas disciplinadoras adotadas por ele (Noce et al., 2009; Brito, 1993). Assim, os professores foram questionados a respeito da eficácia das medidas disciplinadoras em relação ao grupo trabalhado (nível de ensino). Elencou-se possíveis medidas disciplinares, que foram avaliadas em sua eficácia.

A Tabela 2 mostra que a medida considerada como mais eficaz pelo grupo de professores ( $p=91,7 \%)$ foi "reforçar positivamente o aluno" ( $p=2,92 \pm 0,28)$. Ainda de acordo com os professores, de forma geral, outras medidas também foram consideradas como muito eficientes: "dialogar com o aluno" ( $p=2,83 \pm 0,38)$, "organizar as aulas" ( $p=2,83 \pm 0,38)$ e "estabelecer metas" ( $p=2,75 \pm 0,61)$. Todas as medidas são indicadores claros de maturidade e apresentaram índices de eficiência acima de 80\%. Em contrapartida, as medidas consideradas menos eficazes foram: "punir com atividade fisica" $(\mathrm{p}=0,08 \pm 0,41)$ e "ser indiferente ao aluno indisciplinado" ( $\mathrm{p}=0,38 \pm 0,88)$.

Tabela 2 - Eficácia das medidas disciplinadoras adotadas pelos professores

\begin{tabular}{|c|c|c|c|c|c|c|}
\hline & \multirow[b]{2}{*}{ Média } & \multirow[b]{2}{*}{ Desvio } & \multicolumn{4}{|c|}{ Eficácia das medidas (\%) } \\
\hline & & & $\begin{array}{c}0 \\
\text { ineficaz }\end{array}$ & $\begin{array}{c}1 \\
\text { pouco }\end{array}$ & $\begin{array}{c}2 \\
\text { razoável }\end{array}$ & $\begin{array}{c}3 \\
\text { muito }\end{array}$ \\
\hline 01 - Dialogar com o aluno & 2,83 & 0,38 & & & $16,7 \%$ & $83,3 \%$ \\
\hline $\begin{array}{l}02 \text { - Cobrar rigorosamente o } \\
\text { bom resultado }\end{array}$ & 1,71 & 1,00 & $20,8 \%$ & $4,2 \%$ & $58,3 \%$ & $16,7 \%$ \\
\hline 03 - Organizar as aulas & 2,83 & 0,38 & & & $16,7 \%$ & $83,3 \%$ \\
\hline $\begin{array}{l}04 \text { - Exigir que o dançarino } \\
\text { seja dinâmico em suas } \\
\text { atividades }\end{array}$ & 1,87 & 0,61 & & $25,0 \%$ & $62,5 \%$ & $12,5 \%$ \\
\hline $\begin{array}{l}05 \text { - Reforçar positivamente o } \\
\text { aluno }\end{array}$ & 2,92 & 0,28 & & & $8,3 \%$ & $91,7 \%$ \\
\hline 06 - Estabelecer metas & 2,75 & 0,61 & & $8,3 \%$ & $8,3 \%$ & $83,3 \%$ \\
\hline 07 - punir & 0,83 & 0,82 & $41,7 \%$ & $33,3 \%$ & $25,0 \%$ & \\
\hline $\begin{array}{l}08 \text { - Estabelecer normas junto } \\
\text { com os alunos }\end{array}$ & 2,71 & 0,55 & & $4,2 \%$ & $20,8 \%$ & $75,0 \%$ \\
\hline $\begin{array}{l}09 \text { - Punir todo o grupo pela } \\
\text { indisciplina de qualquer } \\
\text { aluno }\end{array}$ & 0,58 & 0,72 & $54,2 \%$ & $33,3 \%$ & $12,5 \%$ & \\
\hline $\begin{array}{l}10 \text { - Procurar conversar } \\
\text { sempre com o grupo }\end{array}$ & 2,67 & 0,70 & $4,2 \%$ & & $20,8 \%$ & $75,0 \%$ \\
\hline
\end{tabular}




\begin{tabular}{|c|c|c|c|c|c|c|}
\hline & \multirow[b]{2}{*}{ Média } & \multirow[b]{2}{*}{ Desvio } & \multicolumn{4}{|c|}{ Eficácia das medidas (\%) } \\
\hline & & & $\begin{array}{c}0 \\
\text { ineficaz }\end{array}$ & $\begin{array}{c}1 \\
\text { pouco }\end{array}$ & $\stackrel{2}{2}$ & $\begin{array}{l}3 \\
\text { muito }\end{array}$ \\
\hline $\begin{array}{l}11 \text { - Punir com atividade física } \\
\text { (correr, abdominal, ...) }\end{array}$ & 0,08 & 0,41 & $95,8 \%$ & & $4,2 \%$ & \\
\hline $\begin{array}{l}12 \text { - Deixar o aluno fora das } \\
\text { atividades }\end{array}$ & 1,38 & 1,01 & $25,0 \%$ & $25,0 \%$ & $37,5 \%$ & $12,5 \%$ \\
\hline $\begin{array}{l}13 \text { - Ser indiferente ao aluno } \\
\text { indisciplinado }\end{array}$ & 0,38 & 0,88 & $79,2 \%$ & $12,5 \%$ & & $8,3 \%$ \\
\hline $\begin{array}{l}14 \text { - Usar sinais (palmas, } \\
\text { comando) para controlar } \\
\text { atividades ou chamar } \\
\text { atenção }\end{array}$ & 2,79 & 0,41 & & & $20,8 \%$ & $79,2 \%$ \\
\hline $\begin{array}{l}15 \text { - Repreender o aluno } \\
\text { particularmente }\end{array}$ & 2,33 & 1,01 & $8,3 \%$ & $12,5 \%$ & $16,7 \%$ & $62,5 \%$ \\
\hline $\begin{array}{l}16 \text { - Repreender o aluno } \\
\text { publicamente }\end{array}$ & 0,58 & 0,78 & $58,3 \%$ & $25,0 \%$ & $16,7 \%$ & \\
\hline $\begin{array}{l}17 \text { - Delegar } \\
\text { responsabilidades aos } \\
\text { aluno }\end{array}$ & 2,08 & 1,06 & $8,3 \%$ & $25,0 \%$ & $16,7 \%$ & $50,0 \%$ \\
\hline $\begin{array}{l}18 \text { - Interromper as aulas } \\
\text { como forma de punição } \\
\text { ao grupo }\end{array}$ & 0,58 & 0,78 & $58,3 \%$ & $25,0 \%$ & $16,7 \%$ & \\
\hline $\begin{array}{l}19 \text { - Fazer comparações } \\
\text { do rendimento de } \\
\text { cada aluno com metas } \\
\text { estabelecidas para o } \\
\text { grupo }\end{array}$ & 1,08 & 1,21 & $45,8 \%$ & $20,8 \%$ & $12,5 \%$ & $20,8 \%$ \\
\hline $\begin{array}{l}20 \text { - Comparar o rendimento } \\
\text { do grupo com metas } \\
\text { estabelecidas }\end{array}$ & 1,79 & 1,14 & $25,0 \%$ & & $45,8 \%$ & $29,2 \%$ \\
\hline
\end{tabular}

Ao comparar a eficácia das medidas disciplinadoras dos professores, de acordo com o gênero, observamos (Tabela 3), de uma forma geral, que o perfil de homens e mulheres foi bem semelhante. Apenas as medidas "organizar as aulas" ( $\mathrm{p}=0,008)$, "punir todo o grupo pela indisciplina de qualquer aluno" $(\mathrm{p}=0,023)$, "repreender o aluno publicamente" $(\mathrm{p}=0,038)$, "interromper as aulas como forma de punição ao grupo" $(\mathrm{p}=0,038)$ foram estatisticamente significantes.

Para comparar a eficácia das medidas disciplinadoras de acordo com a experiência do professor (Tabela 4), foi realizada a distribuição de frequência para o tempo de experiência em ensino e o grupo de professores foi dividido pela metade (percentil 50), sendo considerado menos experientes os professores com menos de 61 meses. Os resultados demonstraram que os professores mais experientes consideram mais eficientes as 
medidas "estabelecer metas" ( $\mathrm{p}=0,014)$ e "usar sinais para controlar as atividades" $(\mathrm{p}=0,05)$. Os menos experientes, em contrapartida, consideram mais eficientes as medidas "punir" ( $\mathrm{p}=0,014)$; "punir todo grupo pela indisciplina de qualquer um" $(\mathrm{p}=0,013)$; "repreender o aluno publicamente" ( $\mathrm{p}=0,022)$ e "interromper as aulas como forma de punição ao grupo" $(\mathrm{p}=0,003)$.

Tabela 3 - Comparação da eficácia das medidas disciplinadoras adotadas pelo professor em relação ao sexo

\begin{tabular}{|c|c|c|c|}
\hline & Masc & Fem & $\begin{array}{l}\text { Valor } \\
\text { de } p\end{array}$ \\
\hline 01 - Dialogar com o aluno & 2,79 & 2,90 & 0,481 \\
\hline 02 - Cobrar rigorosamente o bom resultado & 1,86 & 1,50 & 0,400 \\
\hline 03 - Organizar as aulas & 3,00 & 2,60 & 0,008 \\
\hline 04 - Exigir que o aluno seja dinâmico em suas atividades & 1,86 & 1,90 & 0,870 \\
\hline 05 - Reforçar positivamente o aluno & 2,86 & 3,00 & 0,229 \\
\hline 06 - Estabelecer metas & 2,57 & 3,00 & 0,089 \\
\hline 07 - Punir & 1,00 & 60 & 0,245 \\
\hline 08 - Estabelecer normas junto com os alunos & 2,71 & 2,70 & 0,952 \\
\hline 09 - Punir todo o grupo pela indisciplina de qualquer aluno & ,86 & 20 & 0,023 \\
\hline 10 - Procurar conversar sempre com o grupo & 2,57 & 2,80 & 0,444 \\
\hline 11 - Punir com atividade física (correr, abdominal, ...) & 14 &, 00 & 0,410 \\
\hline 12 - Deixar o aluno fora das atividades & 1,29 & 1,50 & 0,620 \\
\hline 13 - Ser indiferente ao aluno indisciplinado &, 57 & 10 & 0,200 \\
\hline $\begin{array}{l}14 \text { - Usar sinais (palmas, comando) para controlar } \\
\text { atividades ou chamar atenção }\end{array}$ & 2,71 & 2,90 & 0,289 \\
\hline 15 - Repreender o aluno particularmente & 2,64 & 1,90 & 0,074 \\
\hline 16 - Repreender o aluno publicamente & ,86 & 20 & 0,038 \\
\hline 17 - Delegar responsabilidades aos alunos & 2,00 & 2,20 & 0,659 \\
\hline 18 - Interromper as aulas como forma de punição ao grupo & ,86 & 20 & 0,038 \\
\hline $\begin{array}{l}19 \text { - Fazer comparações do rendimento de cada aluno com } \\
\text { metas estabelecidas para o grupo }\end{array}$ & ,93 & 1,30 & 0,472 \\
\hline $\begin{array}{l}20 \text { - Comparar o rendimento do grupo com metas } \\
\text { estabelecidas }\end{array}$ & 1,79 & 1,80 & 0,977 \\
\hline
\end{tabular}




\section{Tabela 4 - Relação da eficácia das medidas disciplinadoras adotadas pelo} professor e experiência

\begin{tabular}{|c|c|c|c|}
\hline & $-\operatorname{Exp}$ & $+\operatorname{Exp}$ & Valor de p \\
\hline 01 - Dialogar com o aluno & 2,70 & 2,93 & 0,151 \\
\hline 02 - Cobrar rigorosamente o bom resultado & 2,00 & 1,50 & 0,235 \\
\hline 03 - Organizar as aulas & 2,90 & 2,79 & 0,481 \\
\hline 04 - Exigir que o aluno seja dinâmico em suas atividades & 1,70 & 2,00 & 0,245 \\
\hline 05 - Reforçar positivamente o aluno & 2,80 & 3,00 & 0,087 \\
\hline 06 - Estabelecer metas & 2,40 & 3,00 & 0,013 \\
\hline 07 - Punir & 1,30 &, 50 & 0,014 \\
\hline 08 - Estabelecer normas junto com os alunos & 2,60 & 2,79 & 0,427 \\
\hline $\begin{array}{l}09 \text { - Punir todo o grupo pela indisciplina de qualquer } \\
\text { aluno }\end{array}$ & 1,00 & ,29 & 0,013 \\
\hline 10 - Procurar conversar sempre com o grupo & 2,40 & 2,86 & 0,118 \\
\hline 11 - Punir com atividade física (correr, abdominal, ...) & ,20 & ,00 & 0,245 \\
\hline 12 - Deixar o aluno fora das atividades & 1,80 & 1,07 & 0,082 \\
\hline 13 - Ser indiferente ao aluno indisciplinado & 60 & 21 & 0,297 \\
\hline $\begin{array}{l}14 \text { - Usar sinais (palmas, comando) para controlar } \\
\text { atividades ou chamar atenção }\end{array}$ & 2,60 & 2,93 & 0,050 \\
\hline 15 - Repreender o aluno particularmente & 2,20 & 2,43 & 0,595 \\
\hline 16 - Repreender o aluno publicamente & 1,00 & 29 & 0,022 \\
\hline 17 - Delegar responsabilidades aos alunos & 1,70 & 2,36 & 0,137 \\
\hline $\begin{array}{l}18 \text { - Interromper as aulas como forma de punição ao } \\
\text { grupo }\end{array}$ & 1,10 & ,21 & 0,003 \\
\hline $\begin{array}{l}19 \text { - Fazer comparações do rendimento de cada aluno com } \\
\text { metas estabelecidas para o grupo }\end{array}$ & 1,00 & 1,14 & 0,783 \\
\hline $\begin{array}{l}20 \text { - Comparar o rendimento do grupo com metas } \\
\text { estabelecidas }\end{array}$ & 1,50 & 2,00 & 0,300 \\
\hline
\end{tabular}

Ao comparar a eficácia das medidas disciplinadoras de acordo com o nível de ensino ao qual o professor está inserido (Figura 2), constatamos que existem medidas consideradas pelo professor com o mesmo nível de eficácia, independentemente do nível de ensino, como por exemplo "organizar aulas" ( $p=0,996)$ e "estabelecer metas" $(p=0,968)$. No entanto, existem medidas que os professores consideraram mais efetivas com os alunos mais velhos (teoricamente mais maduros), como por exemplo "exigir que o aluno seja dinâmico em suas atividades" ( $\mathrm{p}=0,001)$, "cobrar rigorosamente o bom resultado" $\mathrm{e}$ 
"delegar responsabilidades aos alunos". Existem também medidas consideradas pelos professores como mais eficazes para o grupo mais jovem: "punir" $(\mathrm{p}=0,027)$ e "deixar o aluno fora das atividades" ( $\mathrm{p}=0,016)$.

\section{Figura 2 - Comparação da percepção da eficácia das medidas disciplinadoras aplicadas pelo professor de acordo com o nível de ensino em que estão inseridos}

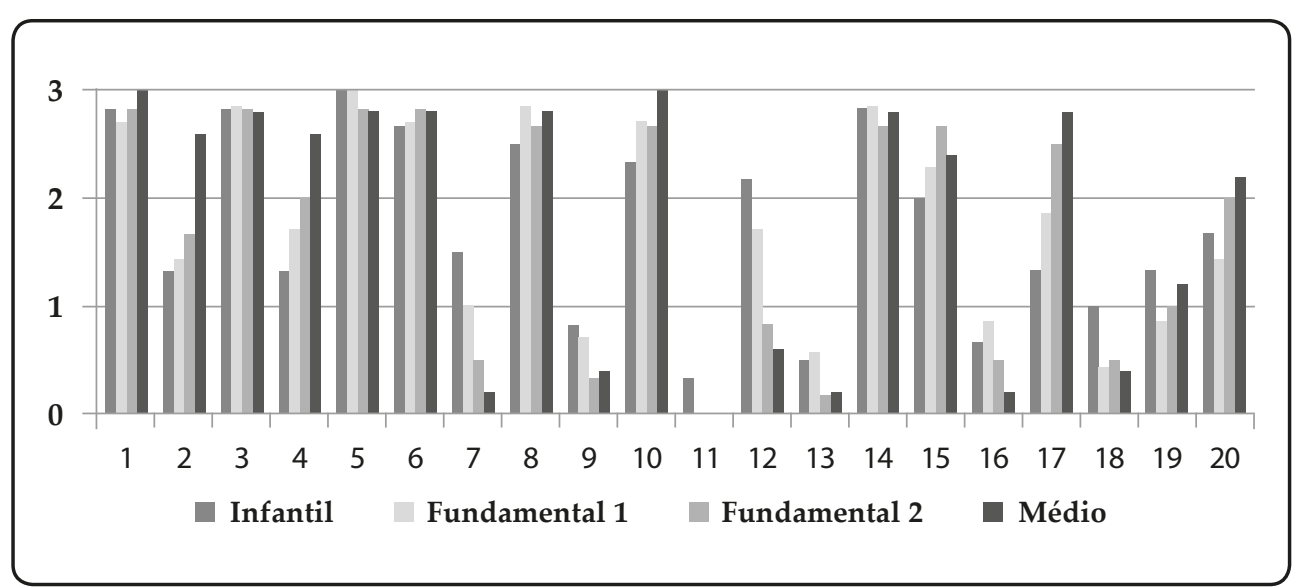

\section{Discussão}

Para avaliar a eficácia das medidas disciplinadoras adotadas por professores durante as aulas de Educação Física, utilizamos um questionário (Brito, 1993), que demonstrou um satisfatório nível de confiabilidade na análise psicométrica realizada em trabalho anterior (Noce et al., 2011). Os principais resultados indicam que as medidas disciplinadoras mais eficazes para grupo de professores foram "reforçar positivamente o aluno", "dialogar com o aluno", "organizar as aulas" e "estabelecer metas". Em contrapartida, as medidas consideradas menos eficazes foram: "punir com atividade física" e "ser indiferente ao aluno indisciplinado". Quando analisamos o estilo de liderança adotado pelos professores, observamos que eles utilizam, predominantemente, o estilo de liderança democrático nas séries mais avançadas, ou seja, com os alunos mais maduros.

Esses achados corroboram dados da literatura, pois diferentes autores (Hersey \& Blanchard, 1986; Noce et al., 2009; Brandão \& Carchan, 2010; Noce et al., 2011; Simim \& Noce, 2012) relacionam o estilo de liderança a ser adotado pelo professor ao nível de maturidade do grupo. Como já mencionado, duas formas de liderança poderão ser desempenhadas pelo professor: a autoritária e a democrática. Na primeira, os alunos são completamente excluídos do processo que envolve qualquer decisão, na segunda 
há o envolvimento dos próprios alunos nas tarefas de direção. Segundo Noce et al. (2009), o líder democrático estimula o grupo com perguntas e problemas em permanente discussão, descrevendo os possíveis passos para o alcance das metas e sugerindo alternativas. Já o líder autocrático reveste-se do poder absoluto e absorve inteiramente a iniciativa do grupo, polarizando na sua pessoa a capacidade de planejar, decidir e controlar todas as ações dos liderados. O estilo de liderança autocrático tende a ser incompatível com um grupo que apresenta maior nível de maturidade, e similarmente, o estilo de liderança democrático não consegue ser muito bem-sucedido quando o grupo de liderados se mostra imaturo. Os professores que compuseram a amostra deste trabalho demonstraram estar alinhados com a literatura, ao adotarem, preferencialmente, o estilo democrático com os alunos mais maduros (Hersey \& Blanchard, 1986; Noce et al., 2009; Noce et al., 2011).

Além do fato do estilo de liderança ser mais efetivo quando está de acordo com a maturidade do grupo, um outro conceito que tem complementado e ampliado esta visão é o conceito da liderança situacional. O modelo de liderança situacional propõe o ajustamento do comportamento do líder, não apenas em função das características do grupo, mas também em função da situação (Noce et al., 2009). Dentro deste modelo, o líder deve ter a capacidade de modificar seu estilo de liderança conforme três componentes essenciais: um que se refere à quantidade de orientação e direção oferecida por ele, denominado comportamento da tarefa; outro que se refere à quantidade de apoio socioemocional proporcionado pelo líder, denominado de comportamento de relacionamento; e por fim, outro indicado pelo nível de prontidão dos subordinados, denominado de maturidade do subordinado. Seguindo este raciocínio, os professores podem transitar de um estilo de liderança a outro, de acordo com as particularidades de cada situação.

Diretamente relacionado ao estilo de liderança, encontram-se as medidas disciplinadoras adotadas pelo professor (Noce et al., 2009; Brito, 1993). Os resultados do nosso trabalho mostraram similaridades quanto à maior e menor eficácia de várias medidas. No entanto, quando comparamos a eficácia das medidas com a experiência dos professores, algumas divergências foram encontradas: enquanto os professores mais experientes consideram mais eficientes as medidas "estabelecer metas" e "usar sinais para controlar as atividades"; os menos experientes, consideram as medidas "punir", " punir todo grupo pela indisciplina de qualquer um", "repreender o aluno publicamente" e "interromper as aulas como forma de punição ao grupo", como mais eficientes.

Especificamente no contexto da Educação Física escolar, e contrariamente ao que observamos em nosso estudo, comportamentos muito significativos na satisfação dos alunos com a liderança do professor envolvem o comportamento direcionado para o ensino e correção das técnicas da respectiva modalidade, bem como a capacidade para explicar e treinar individualmente os alunos nas diferentes competências desportivas (Resende et al., 2013). Esta discrepância encontrada em nosso estudo reflete, claramente, 
a importância da experiência na atuação do professor. Seguindo esta linha de pensamento, alguns autores propõem o conceito de "reflexão-na-ação", segundo o qual, os profissionais aprendem partindo da análise e interpretação da sua própria atividade (Zeichner, 1992; Pérez Gómez, 1992; Pimenta, 2002; Longhini, 2007). Zeichner (1992) pontua que esta "reflexão-na-ação" deve ocorrer sempre que os professores têm necessidade de adaptar uma nova situação originada da ação e desenvolver experiências para conseguir respostas mais adequadas. Nesta fase, o processo a reflexão serve para reformular as ações dos professores no decurso da sua intervenção profissional (Zeichner, 1992).

Conforme Hurtado (1983), o processo educativo tem no aluno o elemento para o qual converge toda a obra educacional, cabendo à escola, através do professor, incentivá-lo, conduzi-lo e orientá-lo para que chegue, por seu próprio esforço e por um processo natural e contínuo, à idade adulta, não importando a soma de conhecimentos adquiridos, mas a maneira como o educando os concebe e os maneja. Em contrapartida, ao longo do processo de escolarização, o professor deve se atentar para não restringir e limitar a ação do aluno, uma vez que esse processo de controle pode acarretar duas consequências, absolutamente interligadas: ao mesmo tempo que pode transformar as ações e o corpo mais eficientes, torna também seus portadores mais dóceis, portanto, mais submissos (Chamliam, 1995). Este autor exemplifica a relação ideal entre liberdade e disciplina com a diferença entre o homem que se submeteu à disciplina para aprender a nadar e o homem que não o fez. O primeiro adquiriu a liberdade na água, enquanto ela falta ao segundo. Paradoxalmente, é certo que uma responsabilidade autodisciplinada só chega como resultado da liberdade, entretanto, no regime da liberdade é imperativo que preparemos os jovens, tão bem quanto possível, para o desenvolvimento da maturidade atrelada à liberdade. Crianças e jovens cujo interesse estejam ativamente engajados em seus estudos não precisam ser policiados. Uma liberdade considerável pode ser-lhes concedida, não para que se evite disciplina genuína, mas para que lhes seja permitido assumir responsabilidades maiores e menos artificiais, cujo desempenho evoque nas crianças o sentimento íntimo de ordem.

No ambiente escolar, a disciplina é um objetivo educacional a ser atingido, sendo fundamental para orientar a ação pedagógica e, portanto, não deve ser entendida apenas como um conjunto de normas (Abud; Romeu, 1989). A disciplina escolar é consequência da organização total da escola, isto é, desde o modo como a escola está preceituada, até o reflexo da relação que se estabelece entre professor e aluno (Haydt, 1998).

No que tange à organização da escola, sabendo que a massi;Torres, 2010), faz-se necessário o empenho para tentar resgatar a qualidade do ensino e a formação dos cidadãos. No que se refere à atuação do professor, é preciso ter em mente um processo contínuo de capacitação e qualificação, para que possa rever e desenvolver competências, a fim de acompanhar a demanda de informações, a introdução de novas tecnologias, a mudança no perfil dos alunos, etc. 


\section{Conclusão}

Em síntese, várias medidas apresentaram um nível de eficácia elevado na percepção dos professores, sendo que "reforçar positivamente o aluno" foi a medida de maior eficácia. Por outro lado, a divergência em algumas medidas nos permite inferir que a eficácia das medidas disciplinadoras também depende do nível de ensino do aluno e da experiência dos professores. Portanto, o nível de maturidade médio do grupo determina o estilo ideal de liderança e, consequentemente, as medidas disciplinadoras mais eficazes para o grupo. Sabendo que a disciplina é fundamental para orientar a ação pedagógica e que não existe um estilo de liderança melhor que outro, o professor precisará desenvolver a liderança situacional, para adequar o melhor estilo às particularidades de cada turma ou grupo de alunos.

Recebido em 04/03/2016 e aprovado em 08/06/2016

\section{Referências}

ABUD, M. J. M.; ROMEU, S. A. A problemática da disciplina na escola: autoridade versus autoritarismo. São Paulo: Ed Pedagógica e Universitária Ltda, EPU, 1989.

ALMESTOY, S. C.; CESTARI, M. E.; THOFHERN, M. B.; BACKES, V. M. S.; MILBRATH, V. M.; TRINDADE, L. L. As percepções dos enfermeiros acerca da liderança. Revista Gaúcha de Enfermagem, v. 30, n. 4, p. 617-624, 2009.

ARAÚJO, K.; FERREIRA, M. A. A. O exercício da liderança por meio estilo coaching na gestão de equipes. Revista Administração em Diálogo, v. 13, n. 2, p. 47-72, 2009.

BOARINI, M. L. Indisciplina escolar: uma construção coletiva. Revista da Associação Brasileira de Psicologia Escolar e Educacional, v. 17, n. 1, p. 123-131, 2013.

BRANDÃO, M. R. F.; CARCHAN, D. Comportamento preferido de liderança e sua influência no desempenho dos atletas. Motricidade, v. 6, n. 1, p. 53-69, 2010.

BRITO, L. T. M. O significado da disciplina no treinamento esportivo: conceitos de treinadores de basquetebol masculino em BH. Dissertação. Escola de Educação Física da UFMG, 1993.

CARVALHO, J. S. F. Os sentidos da (in)disciplina: regras e métodos como práticas sociais. In AQUINO, J. G. (Org.). Indisciplina na escola: alternativas teóricas e práticas. São Paulo: Summus, 1996. p. 129-138.

CHAMLIAM, H. C. Disciplina e liberdade na escola. Revista Paulista de Educação Física, supl.1, p.79, 1995.

DE LA TAILLE, Y. Autoridade na escolar. In: AQUINO, J. G. (org) Autoridade e autonomia na escolar: alternativas teóricas práticas. São Paulo: Summus, 1999. p. 930. 
DOPP, D. A.; PONTES-RIBEIRO, D. H. INDISCIPLINA EM SALA DE AULA: desafio para professor, instituição e família. Revista Transformar, n.6, 2014.

GOMES, R.; PAIVA, P. Liderança, compatibilidade treinador-atleta e satisfação do handebol: percepção de atletas novatos e experientes. Psico-USF, v.15, n.2, p. 235-248, 2010.

HAYDT, R. Curso de Didática Geral. 5ª ed. São Paulo: Editora Ática, 1998.

HERSEY, P.; BLANCHARD, K. Psicologia para administradores: a teoria e as técnicas da liderança situacional. São Paulo: Ed Pedagógica e Universitária Ltda, EPU, 1986.

HURTADO,J.G.G. M. OEnsino da Educação Física: uma abordagem didática. 2ª ed.Curitiba: Educa, 1983.

KOEHLER, Sonia Maria Ferreira. Violência Psicológica: um estudo do fenômeno na relação professor aluno. La nueva alfabetización: un reto para la educación del siglo XXI. Disoinível no site: http://smec.salvador.ba.gov.br/site/documentos/espaco-virtual/espaco-praxis-pedagogicas/ RELA\%C3\%87\%C3\%83O\%20PROFESSOR-ALUNO/violencia\%20psicologica\%20-\%20um\%20 estudo\%20do\%20fenomeno\%20na\%20relacao\%20professor-aluno.pdf

LONGHINI, M. D. A pesquisa sobre a prática como elemento na formação do professor: uma experiência envolvendo a formação inicial de professores de Física. Revista Electrónica de Investigación en Educación en Ciencias, v. 2, n. 1, p. 70-83, 2007.

NASSIF, V. M. J.; HANASHIRO, D. M. M.; TORRES, R. R. Fatores que influenciam na percepção das competências para o exercício da docência, Revista Brasileira de Educação, v. 15, n. 44, p. 364-379, 2010.

NOCE, F.; FOUREAUX, G.; MELO, C. C.; COSTA, G. M. L.; COSTA, V. T. Análise da eficácia das medidas disciplinadoras em um grupo de dança de alto rendimento. Revista Mineira de Educação Física, v. 19, n. 2, p. 84-100, 2011.

NOCE, F.; COSTA, I. T.; LOPES, M. C. Liderança. In: SAMULSKI, D. M. (Org.). Psicologia do Esporte: Conceitos e novas perspectivas. São Paulo: Manole, 2009. p. 295-334.

NOVAIS, E. L. É possível ter autoridade em sala de aula sem ser autoritário? Linguagem \& Ensino, v. 7, n. 1, p. 15-51, 2004.

PÉREZ GÓMEZ, A. O pensamento prático do professor: a formação do professor como profissional reflexivo. In: NÓVOA, A. (org.). Os professores e a sua formação. Lisboa: Dom Quixote, 1992. p. $93-$ 114 .

PIMENTA, S. G. Professor reflexivo: construindo uma crítica. In: PIMENTA, S.G.; GHEDIN, E. (orgs.) Professor reflexivo no Brasil: gênese e crítica de um conceito. São Paulo: Cortez, 2002. p. 30-52.

PIRES, D. B. Disciplina: construção da disciplina consciente e interativa em sala de aula e na escolar. Educação \& Sociedade, v. 20, n. 66, 1999.

RESENDE, R.; GOMES, R.; VIEIRA, O. Liderança no futsal de alta competição: importância dos resultados desportivos. Motriz, v. 19 n. 2, p. 502-512, 2013.

SIMIM, M. A. M.; NOCE, F. Analysis of the profile leadership perceived by the practitioners of capoeira. Motricidade, v. 8, n. s2, p. 956-963, 2012.

TIBA, I. Disciplina: O Limite na Medida Certa. 32ª ed. São Paulo: Gente, 1996.

ZEICHNER, K. M. Novos caminhos para o practicum: uma perspectiva para os anos 90. In: NÓVOA, A. (org.). Os professores e a sua formação. Lisboa: Dom Quixote, 1992. p.115-38. 